\title{
Effect of Pharmacotherapy-Combined Instrument-Assisted Soft Tissue Mobilization on Tissue Extensibility Dysfunction in Recreational Runners - A Randomized Controlled Trial
}

\author{
Prasannajeet Pramod Nikam¹, Govindhan Varadharajulu² \\ ${ }^{1}$ Department of Sports Physiotherapy, Krishna College of Physiotherapy, Karad, Maharashtra, India. \\ ${ }^{2}$ Department of Neuroscience, Krishna College of Physiotherapy, Karad, Maharashtra, India.
}

\section{ABSTRACT}

\section{BACKGROUND}

The definitive efficacy and long-term effects of Instrument Assisted Soft Tissue Mobilization (IASTM) have not been firmly established, due to a lack of research examining lasting fascia structural changes and patient outcomes. We wanted to evaluate as to whether the use of topical muscle relaxant along with M2T® blade would have any effect on the Tissue Extension Disability in recreational runners.

\section{METHODS}

100 subjects were randomly allocated to group A and group B. Group A was asked to perform active stretching whereas group B was given IASTM with topical muscle relaxant. Post-intervention data was recorded.

\section{RESULTS}

The active knee extension test scores for both the groups were determined. A statistically significant improvement $\left(\mathrm{p}<0.0001^{*}\right)$ was seen in both the groups but the mean of post intervention scores of group B (21.64) showed more improvement and were more uniform than group A.

\section{CONCLUSIONS}

The present study concluded that IASTM using M2T blade® when given in combination with a topical skeletal muscle relaxant like Volteran ${ }^{\circledR}$ showed significantly better results in cases of tissue extensibility dysfunction of hamstring muscles in recreational runners.

\section{KEY WORDS}

M2T Blade, IASTM, Tissue Extension Disability, Hamstring Tightness, Runners
Corresponding Author:

Dr. Prasannajeet Pramod Nikam, 68/6, Pratap Gani Peth, Siddha Bungalow, Near AIKYA Press, Satara-415002, Maharashtra, India. E-mail: prasannastaarc@gmail.com

DOI: $10.14260 / \mathrm{jemds} / 2020 / 550$

How to Cite This Article:

Nikam PP, Varadharajulu G. Effect of pharmacotherapy combined instrument assisted soft tissue mobilization on tissue extensibility dysfunction in recreational runners- a randomized controlled trial. J Evolution Med Dent Sci 2020;9(35):25312535, DOI: 10.14260/jemds/2020/550

Submission 17-04-2020,

Peer Review 16-07-2020,

Acceptance 25-07-2020,

Published 31-08-2020.

Copyright (C) 2020 JEMDS. This is an open access article distributed under Creative Commons Attribution License [Attribution 4.0 International (CC BY 4.0)] 


\section{BACKGROUND}

Instrument Assisted Soft Tissue Mobilization (IASTM) is a unique therapeutic intervention primarily used for treating myofascial restriction which is based upon the rationale as proposed by James Cyriax.1,2 It consists of breaking myofascial adhesions using tools designed to serve the same. IASTM differs from the Cyriax approach which utilizes digital cross friction in the fact that application of IASTM is done with the help of specially designed instruments which provide passive relaxation to soft tissue to reduce pain and improve range of motion. ${ }^{2}$ IASTM helps to detect as well as treat fascial restrictions, improve localization and effectively treat areas with various soft tissue dysfunctions like soft tissue fibrosis, chronic inflammation, degeneration etc. Although IASTM treatment has to be combined with other manual or modalitybased therapeutic approaches, it still remains a very popular myo-fascial release tool especially in the athletic population. Graston, M2T Blade, Adhesion Breakers and Fascial Abrasion Technique are some of the popular soft tissue mobilization tools commercially available in the markets. ${ }^{3}$ M2T Blade is a type of IASTM instrument which is used now a days to provide soft tissue mobilisation. The possible mechanism of action hypothesized by various clinicians and practitioners says that IASTM application results in production of localized microtrauma to soft tissue being treated. The repetitive microtrauma induced while applying IASTM ultimately results in micro-vascular and capillary haemorrhage, which in turn triggers the inflammatory process. ${ }^{4,5}$ This inflammatory process re-initiates the healing process of the tissue by optimising the delivery of blood, nutrients, and fibroblasts to the target area. This further facilitates collagen synthesis, deposition, and ultimately maturation. ${ }^{6}$ An alternative theory for explaining the potential mechanism of action of IASTM was proposed by Kivlan et al. (2015). The various theories behind mechanism of IASTM as proposed by him include increase in mobility of the fascia, proliferation of fibroblasts in the ECM, increased vascular supply to the injured tissue as well as decrease in cellular matrix adhesion and localized ischemia. ${ }^{7}$

Theoretically, the main cause of muscle tightness is said to be tissue extensibility dysfunction (TED). ${ }^{8}$ The hamstrings have have a greater tendency to shorten than most of the lower limb muscles in the body. ${ }^{9}$ Patellofemoral Syndrome is a phenomenon in which there is increased patella-femoral compressive force secondary to increased tightness of the hamstrings. ${ }^{10}$ Any structural abnormality of the hamstring muscles will cause movement dysfunction at the lumbar spine, pelvis and lower limbs. Hamstring tightness has also been coupled with low back pain and gait abnormality. ${ }^{11}$ The most common type of injury among athletes are related to hamstrings. Such injuries are time-consuming in context with recovery, costly and also have a direct impact on the current performance level of the athlete. ${ }^{12}$

A study conducted by Weerasekara et al (2010) concluded that $86 \%$ of short distance runners and $61 \%$ of long-distance runners had hamstring tightness. Hamstrings being a two joint muscle, tightness in these muscles can lead to the development of other problems like knee pain. Hamstring tightness may also result in upward pulling of the hip and pelvis, causing them to rotate and ultimately resulting in hip or back pain. Sacroiliac joint pain might be another common problem which could in turn lead to postural problems. Such an alarming prevalence of hamstring tightness necessitated the conduction of this study.

The definitive efficacy and long-term effects of IASTM have not been firmly established, due to a lack of research examining lasting fascia structural changes and patient outcomes. Also in this study, it was hypothesized whether the use of topical muscle relaxant along with $\mathrm{M}^{2}{ }^{\mathrm{T}}{ }^{\circledR}$ blade would have any effect on the Tissue Extension Disability in recreational runners.

\section{METHODS}

This randomized controlled trial was carried out in Krishna hospital and Medical Research centre, Karad. The study design was experimental study. Place of the study was Out Patient Department of Krishna College of Physiotherapy, Karad. Sample size was calculated by setting the level of significance to 0.05 . The sampling method used was simple random sampling. The technique used was Lottery method. 100 chits were made which consisted of 50 chits of group A and 50 chits for group B. Subjects were randomly asked to pick up any one chit from the bowl. The inclusion criteria were- individuals between the age group of 18 to 25 years with a minimum of $15^{\circ}$ knee extension deficit with hip flexed in $90^{\circ}$ were included in the study. Individuals with past history of injury to the hamstrings in previous 2 years or those having low back pain since past 2 months as well as any lumbar and lower limb neurological compromise were excluded.

\section{Outcome Measures}

The Active Knee Extension Hamstring Flexibility Test was used to quantify the amount of active knee extension with hip flexed. The subject was asked to lie supine on a plinth with his/her arms rested on the chest region. Then the hip was passively flexed by the therapist. The opposite leg remained fully extended throughout the test. The leg being tested was actively straightened until the point when the thigh began to deviate from the vertical position or till the point where further movement was not possible by the individual. The thigh angle was recorded at that point using goniometer. Minimum angle of knee flexion with the thigh in straight vertical position was measured. If the individual was able to fully straighten the leg, it was considered as the test was negative and the angle recorded as 0 . If any slight to significant flexion was evident, then it was considered as a positive test.

\section{Procedure}

Ethical clearance was obtained from institutional ethical committee. A total of 120 subjects were screened for inclusion and exclusion criteria. 100 recruited subjects which matched the inclusion criteria were briefed about the study in mother tongue. Written informed consent was taken from each of the participant. Demographic data values along with preintervention scores for Active knee extension test were taken prior to the commencement of the study. Also, each individual was checked for leg-dominance by asking them to kick a football. Participants were randomly allocated either the group A $(n=50)$ or group B $(n=50)$. Subjects from group A were 
asked to perform active stretching of the hamstrings thrice a day for six days per week. The duration of each stretch was 30 sec. Three repetitions were asked to be performed with a rest of 15 seconds between each repetition. Whereas the subjects from group B were given IASTM using $\mathrm{M}^{2} \mathrm{~T}$ blade ${ }^{\circledR}$ along with topical muscle relaxant by a certified practitioner. The intervention for this group consisted of a $45 \mathrm{sec}$ session throughout the length of the muscle i.e., hamstrings. Treatment was given only for the dominant lower limb for both the groups. The frequency of the treatment for group B was thrice per week. The total duration of intervention for both the groups was 6 weeks. Post-intervention data was recorded a day following the completion of the study. Statistical analysis was done and results were obtained.

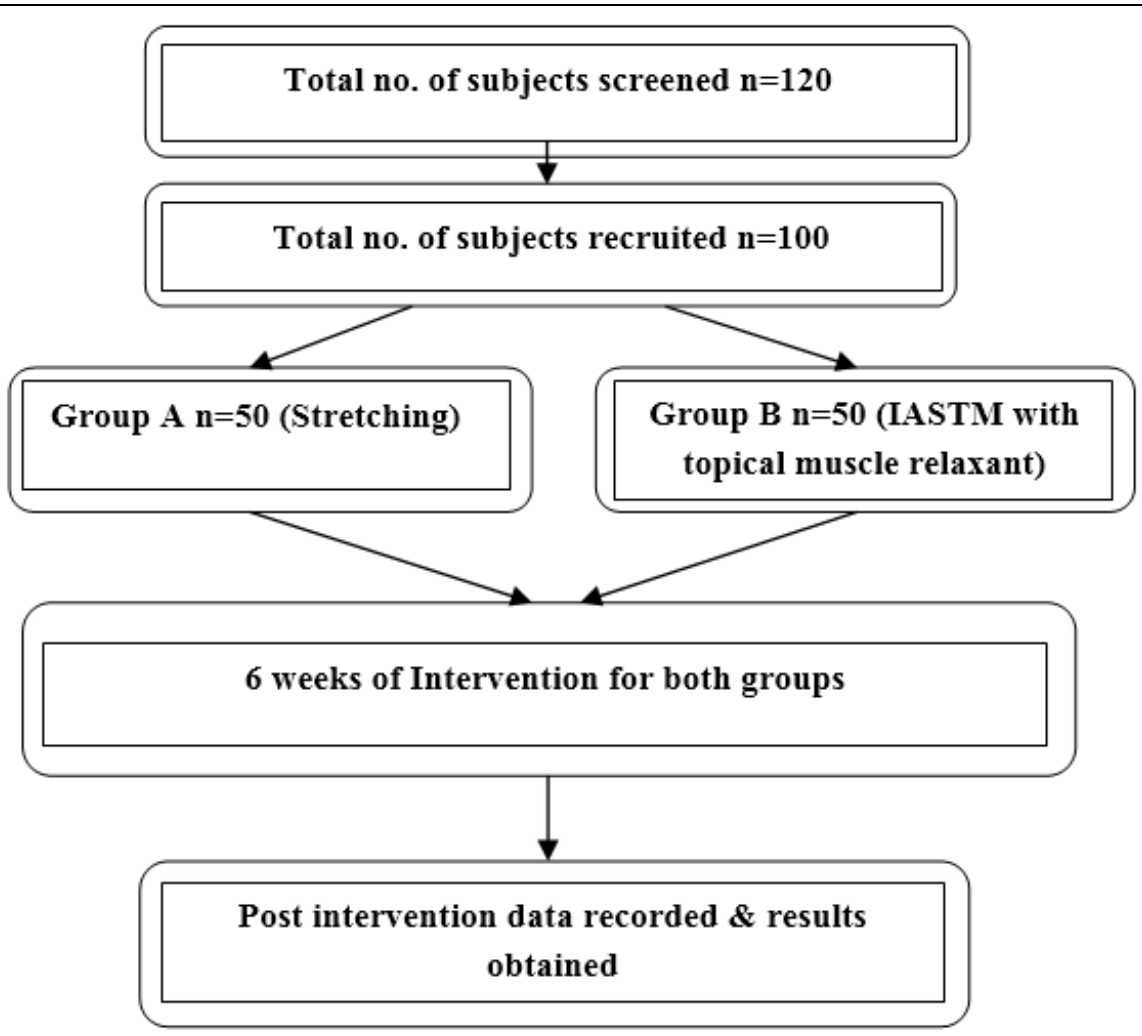

\section{Statistical Analysis}

Statistical analysis of the raw data was done using SPSS software. Both the groups were matched at baseline for anthropometric characteristics like age, height, weight and BMI. The pre-post comparison for both the groups was done using paired t-test. The mean and SD were calculated. Results were obtained.

\section{RESULTS}

\section{Demographic Characteristics}

Both the groups were matched at baseline for age, sex and BMI. Group A had 27 male and 23 female whereas group B had 22 male and 28 female subjects. The subjects included in the study ranged from 20 to 25 years of age.

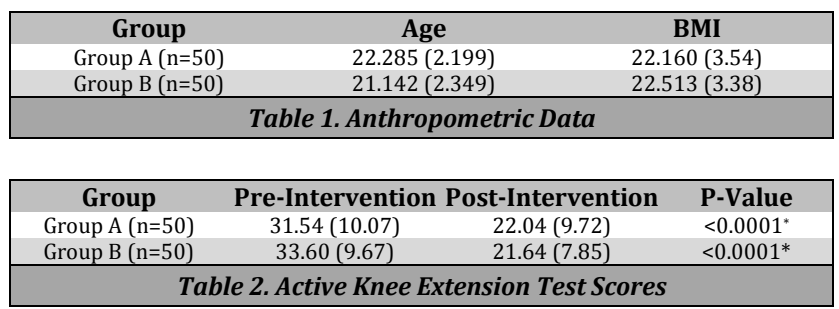

Table 1.1 depicts the baseline data for various anthropometric measures like age and BMI. Uniformity in age group was seen in both the groups.

Table 1.2 represents the active knee extension test scores for both the groups. A statistically significant improvement $\left(\mathrm{p}<0.0001^{*}\right)$ was seen in both the groups but the mean of post intervention scores of group B (21.64) showed more improvement and were more uniform than group A.

\section{DISCUSSION}

In this present study, it was hypothesized that IASTM if combined with application of a topical muscle relaxant like Voltaren ${ }^{\circledR}$ would be effective in treating Tissue Extensibility Dysfunction of the hamstring muscles in recreational runners. According to the study conducted by Weerasekara et al (2010), hamstring tightness is more prevalent in runners. The hamstring muscles are a group of 3 muscles originating from the pelvis and inserting on to the knee. During running, these muscles cause bending the knee and bringing the thigh behind our body. During closed kinematic exercises these muscles work closely with the gluts and calf muscles to facilitate propulsion of the body in the forward direction. In a runners hamstrings help both in production of the necessary forces for 
the flight phase of running, as well as in assisting deceleration of the leg in preparation for heel or foot strike. Owing to this vital part, the hamstrings are at greater risk for both overuse as well as traumatic injuries.

The principal action of hamstrings is flexion of the knee and extension of the thigh. These motions are more prominently seen in the running cycle during the stance phase, i.e. when one foot is fixed firm on the ground and the whole body starts to propel itself forward, and push-off, when the leg must remain behind the body until it has to swing back to the front. The importance of the quadriceps and calf muscles will be addressed by most of the runners for the above mentioned phases of running owing to their specific need to concentrically contract to get through the motions. Quadriceps have a key role to play in the entire stance phase being the primary muscle responsible for extending the knee. Therefore, right from initial contact phase till the forward propulsion, the quads keep on contracting at a constant phase to control the extend of knee extension throughout the push-off phase.

Blanchette and Norman studied the efficiency of IASTM in treating lateral Epicondylitis. ${ }^{13}$ Both groups showed improvement with no significant difference in any of the outcome measures noted. There is evidence of many research studies in literature which have highlighted the therapeutic effects of IASTM at the cellular level. The various therapeutic effects of IASTM which have been observed at the cellular level include increased fibroblast growth activity, reduction in size and shape of scar tissue, increased blood supply as well as the remodelling of collagen fiber matrix. Fibroblast being the most important cell in the extra-cellular matrix. The ECM repairs, regenerates and maintains soft tissue. The fibroblast synthesizes the ECM, which includes very crucial elements like collagen, elastin and proteoglycans.

Effects of three varying degrees of IASTM pressures was investigated by Gehlsen et al. ${ }^{14}$ Direct co-relation was seen between pressure with which the IASTM was applied by the clinician and fibroblast production. Similar results were obtained and confirmed by Davidson et al by using electron microscopy to analyse tissue samples following IM application. ${ }^{15}$

Although no study has been conducted till date which has assessed the combined effect of IASTM and topical muscle relaxant, Markovic et al ${ }^{16}$ carried out a research which compared IASTM with foam roller. The technique used was Fascial Abrasion Technique ${ }^{\circledR}$ and the muscles targeted were quadriceps and hamstrings. Comparison of the immediate effect of a single session of both the techniques revealed that IASTM had a long lasting effect on tissue extensibility than foam roller. The result of the current study are also in accordance with the above mentioned study. Even though both the groups showed statistically significant improvements in the Active Knee Extension Test scores, group B showed more improvement in hamstring extensibility than group A. Also the results in group B were more consistent as compared to group A.

The mechanism involved behind IASTM increasing tissue extensibility is believed to be targeting the adhesions (Heinecke et al., 2014). Friction of the instrument with the treatment surface produces heat causing reduced tissueviscosity and thus ultimately making it softer (Markovic, 2015). In other words, decrease in the viscosity of tissue results in increased extensibility and in turn improves ROM
(Ostojic et al., 2014). The use of topical skeletal muscle relaxant like Volteran ${ }^{\circledR}$ might have added up to the physiological effects of IASTM.

The IASTM treatment using M2T blade was given every $3^{\text {rd }}$ day as the soreness needed to be given time to resolve. A statistically significant improvement $\left(p<0.0001^{*}\right)$ was seen in both the groups but the mean of post intervention scores of group B (21.64) showed more improvement and were more uniform than group A. This could be attributed to the fact that the combination of the topical skeletal muscle relaxant like Volteran ${ }^{\circledR}$ and IASTM resulted in more increase in hamstring flexibility than IASTM alone. Thus, this combination can be advocated as a standard treatment protocol for treating as well as preventing Tissue-Extension Dysfunction in case of recreational runners. Further studies should be directed to check the effect of this combination in cases of other muscles of the body. Also the studies should be carried out with larger sample size and with professional runners.

\section{CONCLUSIONS}

IASTM using M2T blade ${ }^{\circledR}$ when given in combination with a topical skeletal muscle relaxant like Volteran ${ }^{\circledR}$ gives significantly better results in cases of tissue extensibility dysfunction of hamstring muscles in recreational runners.

Financial or Other Competing Interests: None.

\section{REFERENCES}

[1] Baker RT, Hansberger BL, Warren L, et al. A novel approach for the reversal of chronic apparent hamstring tightness: a case report. Int J Sports Phys Ther 2015;10(5):723-33.

[2] Baker RT, Nasypany A, Seegmiller JG, et al. Instrument assisted soft tissue mobilization treatment for tissue extensibility dysfunction. International Journal of Athletic Therapy and Training 2013;18(5):16-21.

[3] Cheatham SW, Lee M, Cain M, et al. The efficacy of instrument assisted soft tissue mobilization: a systematic review. J Can Chiropr Assoc 2016;60(3):200-11.

[4] Melham TJ, Sevier TL, Malnofski MJ, et al. Chronic ankle pain and fibrosis successfully treated with a new noninvasive augmented soft tissue mobilization technique (ASTM): a case report. Med Sci in Sports Exerc 1998;30(6):801-4.

[5] Gross MT. Chronic tendinitis: pathomechanics of injury, factors affecting the healing response and treatment. J Orthop Sports Phys Ther 1992;16(6):248-61.

[6] Hammer WI. The effect of mechanical load on degenerated soft tissue. J Bodyw Mov Ther 2008;12(3):246-56.

[7] Kim J, Sung DJ, Lee J. Therapeutic effectiveness of instrument-assisted soft tissue mobilization for soft tissue injury: mechanisms and practical application. J Exerc Rehabil 2017;13(1):12-22. 
[8] Cook G. Movement: functional movement systems: screening, assessment and corrective strategies. Santa Cruz, California, U.S.A: On Target Publications 2010.

[9] Starring DT, Gossman RM, Nicholson CG, et al. Comparison of cyclic and sustained passive stretching using a mechanical device to increase resting length of hamstring muscles. Phys Ther 1988;69(3):314-20.

[10] Odunaiya NA, Hamzat TK, Ajayi OF. The effects of static stretch duration on the flexibility of hamstring muscles. African J Biomed Res 2005;8(2):79-82.

[11] Kotteeswaran K, Snigdha J, Alagesan J. Effect of proprioceptive neuromuscular facilitation stretching and dynamic soft tissue mobilization on hamstring flexibility in subjects with low back ache - single blinded randomised controlled study. Int J Pharma and Bio Sci 2014;5(3B):228-33.

[12] Weerasekara I, Kumari I, Weerarathna N, et al. The prevalence of hamstring tightness among the male athletes of university of peradeniya in 2010. Int J Phys Med Rehabil 2013;1(1):108.
[13] Blanchette MA, Normand MC. Augmented soft tissue mobilization vs natural history in the treatment of lateral epicondylitis: a pilot study. J Manipulative Physiol Ther 2011;34(2):123-30.

[14] Gehlsen GM, Ganion LR, Helfst R. Fibroblast responses to variation in soft tissue mobilization pressure. Med Sci Sports Exerc 1999;31(4):531-5.

[15] Davidson CJ, Ganion LR, Gehlsen GM, et al. Rat tendon morphologic and functional changes resulting from soft tissue mobilisation. Med Sci Sports Exerc 1997;29(3):313-9.

[16] Markovic G. Acute effects of instrument assisted soft tissue mobilization vs. foam rolling on knee and hip range of motion in soccer players. J Bodyw Mov Ther 2015;19(4):690-6. 